\title{
Reconstruction of the UV-time series weighted for the plant action spectrum based on the UV and total ozone data collected at Belsk, Poland in the period 1992-2003 \\ Piotr Sobolewski*
}

Address: Institute of Geophysics, Polish Academy of Sciences, Warsaw, Poland

Email: Piotr Sobolewski* - piotrs@igf.edu.pl

* Corresponding author

from Cell Biology of Nitric Oxide and Cell Death in Plants

Yalta, Ukraine, 8-II September 2004

Published: 3I May 2005

BMC Plant Biology 2005, 5(Suppl I):S30 doi:I0.I I86/I47I-2229-5-SI-S30

The UV observations weighted for the plant action spectrum are rather limited. The activities in the UV groundbased measurements mainly focused on the human erythemal effects. The objective of this work is to find the long-term variations in the UV radiation weighted by the plant effects using the data (erythemal UV irradiance and total ozone measurements) collected at Belsk $(52 \mathrm{~N}, 21 \mathrm{E})$, Poland, in the period 1992-2003.

The transfer function from the erythemal weighted UV radiation to the UV radiation convolved with the plant action spectrum is constructed using total ozone observations (from the Brewer spectrophotometer) and UV spectral and UV erythemal data (from the Brewer spectrophotometer and the broadband UV biometer SL 501 for the erythemal effects) taken during the intercomparison campaign of the spectrophotometers in Warsaw, May 2004. The long-term variations in the reconstructed data are discussed concerning the impact of total ozone and cloudiness fluctuations on the UV radiation for the period 1992-2003.

\section{Conclusion}

Reasonable reconstruction of the UV irradiance weighted by the higher plants action spectrum is possible if the erythemal UV irradiance and total ozone data are available. The erythemal irradiance is measured for many European sites by various broadband instruments. Thus, for many stations having also total ozone data (ground-based or from satellite observations) we can calculate the UV irradiance weighted by various biological effects.

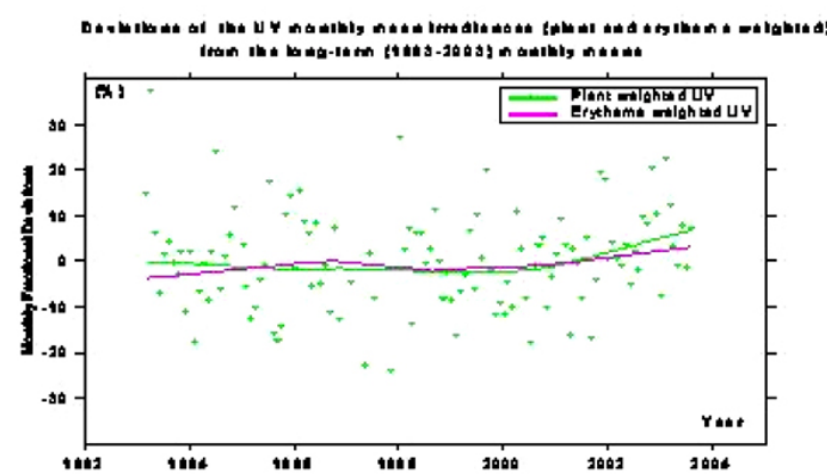

Figure I

The retrieved time series of the monthly fractional deviations of the UV radiation weighted by the plant action spectrum

\section{References}

I. Flint SD, Caldwell MM: A biological spectral weighting function for ozone depletion research with higher plants. Physiol Plant 2003, I I 7:137-144. 